\title{
AOR
}

Selected Papers of \#AolR2020:

The 22nd Annual Conference of the

Association of Internet Researchers

Virtual Event / 13-16 Oct 2021

\section{CROSS-CULTURAL STORYTELLING APPROACHES IN TIKTOK'S MUSIC CHALLENGES}

\author{
Arantxa Vizcaíno-Verdú \\ University of Huelva \\ Crystal Abidin \\ Curtin University
}

\section{Introduction}

Through visual effects, stickers, GIFs, filters, augmented reality, split screens, and transitions in videos no longer than 60 seconds, TikTok has created new strategies that have impacted the music industry (Bereznak, 2019), growing in popularity especially over mass prolonged self-isolation during the COVID-19 pandemic. In the genre of music TikTok posts, we find a mode of interdependence where users demonstrate the cultural value of music through challenge memes, by using their talents, attitudes, and skills to partake in a community drawn together via a music-based affiliation or homophily.

Following a personalised 'For You' feed comprising a recommendation system built on user preferences and interactions, TikTok has created new ways of relating and storingtelling through music (Vizcaíno-Verdú et al., 2021). The platform offers a space for performance, relying especially on music, gestures, and choreographies to tell stories. In our study, we focus specifically on storytelling through TikTok music challenge memes (\#MusicChallenge), with the aim of understanding its cross-cultural significance for users.

\section{Methodology}

This study focuses on a popular social trend on TikTok known as 'music challenges'. Prior studies have focused on TikTok's audio memes and texture of sound (Abidin, 2021); its audio library capabilities to identify emotions, interactivity, and usability through communities (Feng et al., 2019); and its role in spreading political messages through music (Medina-Serrano et al., 2020). Building on this, we focus on the significance and cultural meaning of music challenge memes through five key elements - image, audio, text, story, culture - to understand what comprises a 'challenge' on TikTok, how 
storytelling constitutes music challenges, and what cross-cultural in-group affiliations are identified in this trend.

We developed a 'TikTok music storytelling codebook' informed by grounded theory to analyse categories (codes) (Glaser \& Strauss, 2017). This was informed by our observations of the visible elements of TikTok, prior scholarship on the storytelling aspects of TV music videos (Sedeño-Valdellós et al., 2016), and our initial survey of 'challenge tagging' practices on social media (see Table 1).

\begin{tabular}{|c|c|c|}
\hline Code & Details & When to use \\
\hline \multicolumn{3}{|l|}{ Image } \\
\hline $\begin{array}{l}\text { Filter } \\
\text { Lighting } \\
\text { Effect } \\
\text { Animation } \\
\text { Speed } \\
\text { Sticker } \\
\text { Transition }\end{array}$ & $\begin{array}{l}\text { Portrait, landscape, food, vibe... Color tone adjustment of the image. } \\
\text { Key light, fill light, back light. } \\
\text { Green screen, still images, cuts, compilations, duets, reacts... } \\
\text { Drawings, 3D modeling... } \\
0.3 x, 0.5 x, 1 x, 2 x, 3 x \ldots \\
\text { Decorative, mood, nature and/or lifestyle GIFs or emojis. } \\
\text { Cut, mix / dissolve / crossfade, fade, wipe... }\end{array}$ & $\begin{array}{l}\text { Music videos with visual content } \\
\text { modifying or giving a different } \\
\text { meaning to the story. }\end{array}$ \\
\hline \multicolumn{3}{|c|}{ 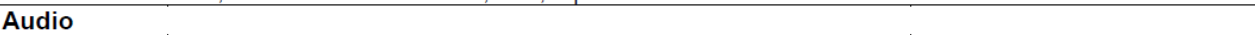 } \\
\hline $\begin{array}{l}\text { Performance } \\
\text { Music } \\
\text { Voice } \\
\text { Silence } \\
\text { Sound effect }\end{array}$ & $\begin{array}{l}\text { User performing someone else's audio/label song. } \\
\text { Original, overlay, remixed, duet, cover... } \\
\text { Real human sound effects (voices, screams...). } \\
\text { Silence resources use. } \\
\text { Diegetic and non-diegetic sounds. }\end{array}$ & $\begin{array}{l}\text { Music videos whose audio is } \\
\text { used to imitate, reply, modify or } \\
\text { change the meaning of the story. }\end{array}$ \\
\hline \multicolumn{3}{|c|}{ - } \\
\hline $\begin{array}{l}\text { Overlay } \\
\text { Caption } \\
\text { Hashtag } \\
\text { Paralanguage }\end{array}$ & $\begin{array}{l}\text { Text overlaid on the screen. } \\
\text { Text attached to the video description. } \\
\text { Hashtag attached to the video. } \\
\text { Performer's non-verbal communication. It is about signs or indications } \\
\text { that contextualize the interpretation: surprise, anger, excitement... }\end{array}$ & $\begin{array}{l}\text { Music videos including text that } \\
\text { modifies or provides additional } \\
\text { meaning to the video. }\end{array}$ \\
\hline \multicolumn{3}{|c|}{ e } \\
\hline $\begin{array}{l}\text { Aesthetics } \\
\text { Topic } \\
\text { Genre } \\
\text { Performer } \\
\text { Challenge }\end{array}$ & $\begin{array}{l}\text { Music and image linkage: movement or kinetic, syntagmatic or content. } \\
\text { Video theme: humorous, protesting, nostalgic, romantic... } \\
\text { Music genre: pop, rock, instrumental, folk, jazz, classical... } \\
\text { Role of the video user(s). } \\
\text { Description of challenge. }\end{array}$ & $\begin{array}{l}\text { Music videos that link the } \\
\text { musical concept and the image. }\end{array}$ \\
\hline \multicolumn{3}{|c|}{ (2) } \\
\hline $\begin{array}{l}\text { Generation } \\
\text { Geography } \\
\text { Language } \\
\text { Genre }\end{array}$ & $\begin{array}{l}\text { Age group: millennial, baby boomer, } Z \ldots \\
\text { Geographic area highlighted in the video (if any). } \\
\text { Language mainly used in the video, or a combination of several. } \\
\text { Music affiliation genre. }\end{array}$ & $\begin{array}{l}\text { Music videos showing a cultural } \\
\text { value that explicitly refers to the } \\
\text { generation (age), location, race, } \\
\text { language of the performers. }\end{array}$ \\
\hline
\end{tabular}

The data comprised 150 music challenge meme posts collected via manual scraping the "\#MusicChallenge" hashtag on TikTok 1-3 April 2021. Posts with the following qualities were excluded from the sample: Using the hashtags without actually engaging in the challenge; giving meta-commentary about the challenge without actually engaging in it; posts in languages outside of our foci. Our study focused on posts in English $(n=122)$, Spanish $(n=17)$, Portuguese $(n=7)$ and French $(n=1)$, as these were the four languages and cultural contexts the authors were equipped to study.

\section{Preliminary results}

First, these challenges display a cultural membership that unifies musical preferences through audio memes and common interests. We noted some examples relating to nostalgia (e.g. identifying songs from the 1960s, Generation Z), fandom (e.g. level of loyalty to and knowledge of a TV series) or humour (e.g. how a TikTok challenge develops between friends) (see Figure 1). 

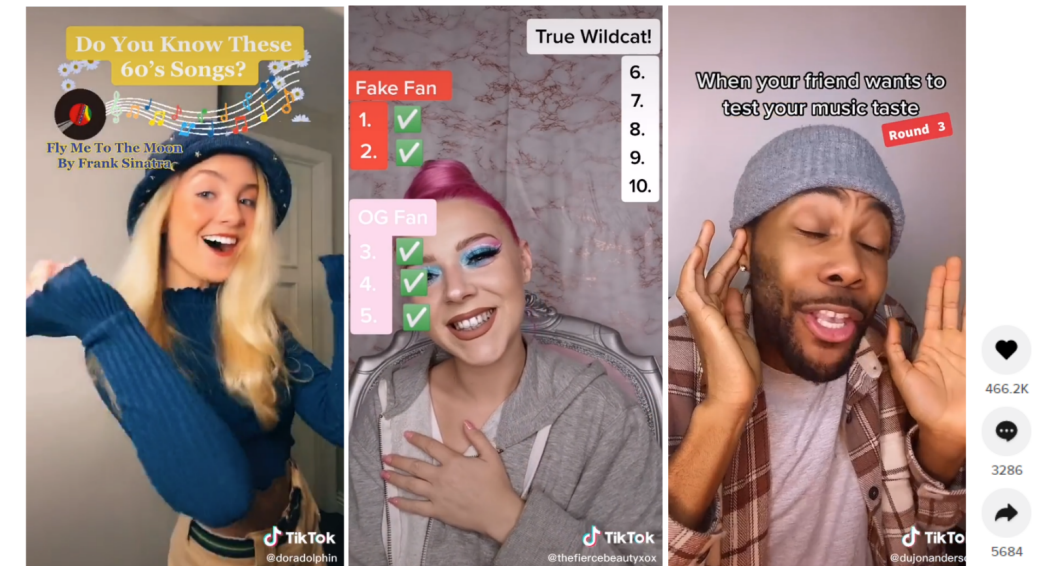

Figure 1. Musical affiliation through nostalgia, fandom, and humour.

Second, this trend is constituted as a storytelling mode. This means that the challenge goes beyond a mere competition. In Figure 2, we see examples where the TikToker expresses emotion when recalling songs from a particular genre of music (e.g. pop-rock), or belonging to an urban tribe (e.g. emo). From a sociological perspective, urban tribes refer to city youths gathered in small, fluid groups that share interests from mainstream cultures (Friedman \& McNabb, 2014). When the TikToker dares users with the text "How emo are you?" and joins in, they are claiming authority and belonging to that tribe.

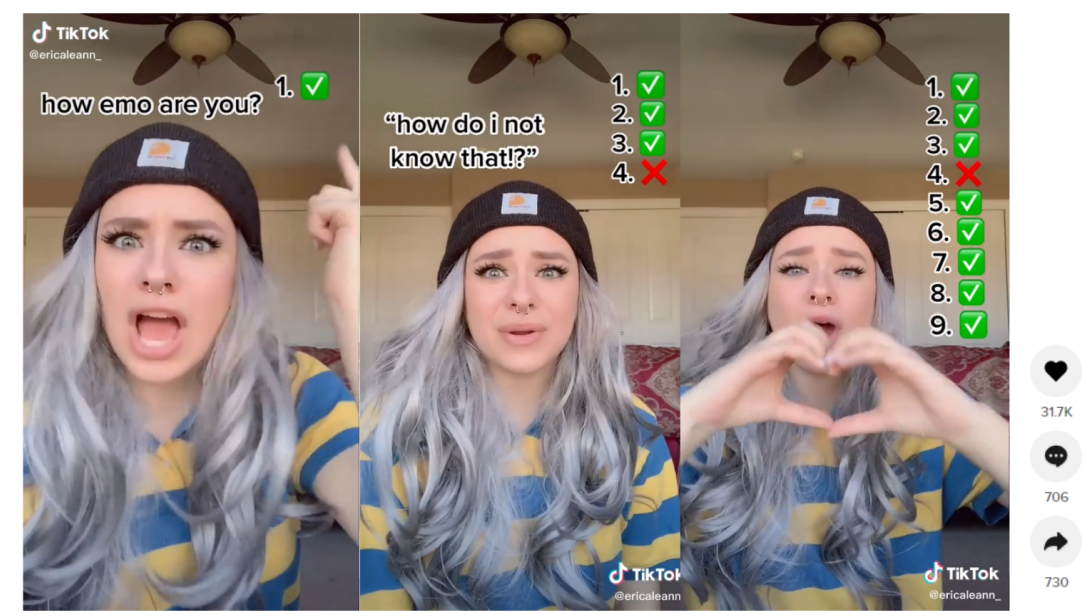

Figure 2. Cultural storytelling: Example of urban tribes.

Third, group affiliations play an essential role in the cultural definition of the musical challenge on TikTok (Figure 3). In this preliminary analysis we found that the two most prominent affiliations (generational by year or generation, and musical genre by TikTokers' musical tastes) were performed in everyday contexts, using limited setting resources and TikTok features (e.g. text overlay). 


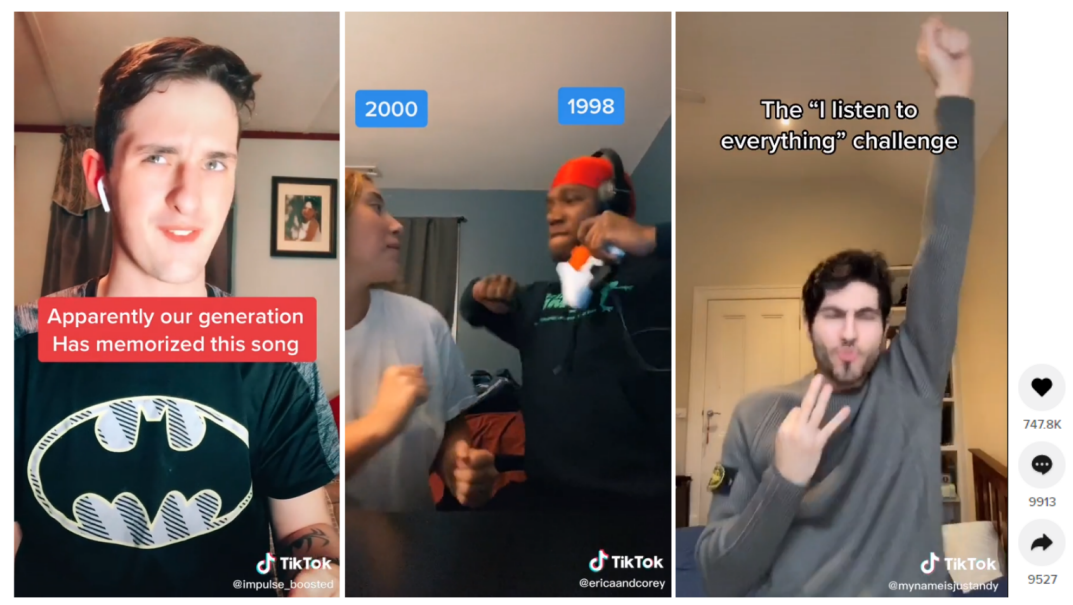

Figure 3. Generational and music genre affiliations examples.

Fourth, there are patterns in how some features of TikTok are used more frequently than others in this challenge. For instance, there is a limited use of transitions, as TikTokers focus on a single-take with no cut-scenes in their lip-syncing, singing, and reactions. Text is also frequently employed to shape meaning to the storytelling, via internal monologues or role-playing dialogue displayed in overlay text.

Most critically, we underscore the identity-cultural character of this pilot analysis. In many cases where pre-2000s songs are posted, the TikTokers are especially young, and often born after the musical era. At times, these young TikTokers exhibited an 'imagined nostalgia' for a period of musical history they may know little about, while demonstrating a desire to 'reminisce' and find affiliation with others above their age group in an act of taste-making. This generation-identity connection by music or lifestyle (sub)culture interests shows a kind of homophily emphasised by audio memes.

Beyond "put a finger down" challenges and "I know the song/l don't know the song" lists, we find a broader significance in telling stories grounded across cultures: sharing a childhood memory, relating to a lifestyle type, and fanning after a musical genre. Beyond this pilot study, we have significantly developed our analysis in a paper under review, which focuses on new modes of new modes of storytelling through audio memes (a unique norm on TikTok) in which musical threads (e.g. social media chatting) are created through duets or reactions (a unique feature on TikTok). We noted a musical-peer group belonging trend that brings out a mixture of urban tribes, emotions, and experiences via creative song-mixing that lasts seconds - A unique experience that differentiates TikTok from other platforms such as YouTube, that extends music videos for topics, musical instruments, skills, and minutes on end. Thus, we understand that TikTok music challenges emerge as a vehicle for interdependent groups to showcase their in-group identities through a new transmedia music flow that turns the "For you page" into a "For Us Network". 


\section{References}

Abidin, C. (2021). Mapping Internet celebrity on TikTok: Exploring attention economies and visibility labours. Cultural Science Journal, 12(1), 77-103. https://doi.org/10.5334/csci.140

Bereznak, A. (2019). Memes are the new pop stars: How TikTok became the future of the music industry. http://bit.ly/30fSYwE

Feng, Y. L., Chen, C. C., \& Wu, S. M. (2019). Evaluation of charm factors of short video user experience using FAHP - A case study of Tik Tok app. In IOP Conference Series Materials Science and Egineering (pp. 1-5). IOP Publishing. https://doi.org/10.1088/1757-899X/688/5/055068

Glaser, B. G., \& Strauss, A. L. (2017). The discovery of grounded theory. Strategies for qualitative research. Routledge.

Liikkanen, L. A., \& Salovaara, A. (2015). Music on YouTube: User engagement with traditional, user-appropriated and derivative videos. Computers in Human Behavior, 50, 108-124. https://doi.org/10.1016/j.chb.2015.01.067

Friedman, R., \& McNabb, N. (2014). The lifestyle of the 'urban tribe'. Florida Communication Journal, 42(1), 61-77.

Medina-Serrano, J. C, Papakyriakopoulos, O., \& Hegelich, S. (2020). Dancing to the Partisan beat: A first analysis of political communication on TikTok. In 12th ACM Conference on Web Science (WebSci '20) (pp. 257-266). ACM. https://doi.org/10.1145/3394231.3397916

Sedeño-Valdellós, A., Rodríguez-López, J., \& Roger-Acuña, S. (2016). The posttelevision music video. A methodological proposal and aesthetic analysis. Revista Latina de Comunicación Social, 71, 332-348. https://doi.org/10.4185/RLCS-2016-1098

Vizcaíno-Verdú, A., Aguaded, I., \& Contreras-Pulido, P. (2021). Understanding transmedia music on YouTube through Disney storytelling. Sustainability, 13(7), 117. https://doi.org/10.3390/su13073667 